\title{
Enhanced conversion of xylan into furfural using acidic deep eutectic solvents with dual solvent and catalyst behavior
}

\author{
Eduarda S. Morais ${ }^{[a]}$, Mara G. Freire ${ }^{[a]}$, Carmen S.R. Freire ${ }^{[a]}$, João A. P. Coutinho ${ }^{[a]}$ and Armando J. D. \\ Silvestre ${ }^{[a]}$ *
}

\begin{abstract}
An efficient process for furfural production from xylan using acidic deep eutectic solvents (DES), acting both as solvents and catalysts, is here disclosed. DES composed of cholinium chloride $([\mathrm{Ch}] \mathrm{Cl})$ and malic acid or glycolic acid at different molar ratios, and the effects of water and $\mathrm{y}$-valerolactone (GLV) contents, solid/liquid $(S / L)$ ratio and microwave heating were investigated. The best furfural yields were obtained with the DES [Ch]Cl:Malic Acid (mole ratio 1:3) + 5 wt.\% of water, under microwave heating for $2.5 \mathrm{~min}$ of reaction time, at $150{ }^{\circ} \mathrm{C}$, at a $\mathrm{S} / \mathrm{L}$ ratio of 0.050 , and $\mathrm{GLV}$ at a weight ratio of $2: 1$. Under these conditions, a remarkable furfural yield (75\%) was achieved. Direct distillation of furfural from the DES-GLV solvent and distillation from 2-methyl-tetrahydrofuran (2-Me-THF) after a back-extraction step were studied for furfural recovery, achieving $89 \%$ of furfural recovery from 2 -Me-THF. This strategy allows the DES-GLV recycling, for at least three times, with no significant furfural yield losses $(>69 \%)$. This is the fastest and highest yield process reported up to date for furfural production, using bio-based DES as solvents and catalysts, paving the way for the process scale-up.
\end{abstract}

\section{Introduction}

The fast depletion of fossil resources and the environmental impact associated with their use led to an increased focus on the utilization of renewable resources, viz biomass, to supply society with commodities. ${ }^{[1]}$ It is estimated that at least $30 \%$ of all chemicals will be derived from renewable resources by $2050 .^{[2]}$ Furfural is amongst the most relevant value-added compounds derived from biomass. It has been identified by the US Department of Energy (DOE) as one of the top 12 value-added chemicals obtained from biomass, with a world market of 300,000 tons per year. ${ }^{[3]}$ Furfural is a precursor of other relevant chemicals, such as furfuryl alcohol, 2-methyltetrahydrofuran (2Me-THF), furan and tetrahydrofuran, which can be used as solvents, intermediates for fragrances and pharmaceuticals, among other applications. ${ }^{[4]}$

${ }^{[a]}$ E. S. Morais, Dr. M. G. Freire, Dr. C. S. R. Freire, Prof. J. A. P. Coutinho and Prof. A. J. D. Silvestre*

CICECO - Aveiro Institute of Materials, Chemistry Department, University of Aveiro, Portugal;

E-mail address: armsil@ua.pt; Tel: +351 234370701

Supporting Information: [figure related to time optimization of the microwave heating process; characterization of the recovered furfural and recycled DES; parameters evaluated for the conventional and microwave heating reactions]. For this article is given via link at the end of the document.
Furfural can be produced from xylose by acid dehydration, which in turn can be obtained from hemicelluloses, one of the three main fractions of lignocellulosic biomass. ${ }^{[4,5]}$ Furfural can also be produced from xylans ${ }^{[6,7]}$ and whole biomass. ${ }^{[8,9]}$ The first furfural industrial production process dates back from 1921, with the Quaker Oats batch process using oat hulls. ${ }^{[10]}$ The furfural production was accomplished in acidic media using Brønsted acids as homogeneous catalysts, such as hydrochloric or sulphuric acids, and temperatures ranging between 160 and $200{ }^{\circ} \mathrm{C} \cdot{ }^{[8,11]}$ In addition to furfural yields below $50 \%,{ }^{[4]}$ these harsh conditions also required high energetic inputs and brought significant environmental and safety concerns. These downsides led to the closing of most batch-based plants for furfural production. A continuous process was later developed by Quaker Oats, increasing the furfural yields up to $55 \%$; nonetheless, the developed process required a high maintenance $\operatorname{cost}^{[11]}$ and was shut down in 1997. [10] Since then, different industrial processes have been proposed. To the best of our knowledge, the highest yield reported so far is $83 \%$, demanding the use of pentosans and of an extra isolation step. Currently, furfural is mainly produced from agricultural wastes, such as corn cobs and sugar cane bagasse. ${ }^{[4]}$ Aqueous media are often used in presence of homogeneous catalysts, like $\mathrm{H}_{2} \mathrm{SO}_{4}$ and $\mathrm{HCl}$, or heterogeneous catalysts, such as aluminum sulphate $\left(\mathrm{Al}_{2}\left(\mathrm{SO}_{4}\right)_{3}\right)^{[7]}$ or tin tetrachloride $\left(\mathrm{SnCl}_{4}\right)^{[6]}$. However, all these processes require the use of high temperatures (170$240{ }^{\circ} \mathrm{C}$ ) and strong acids..$^{[10]}$

Continuous research efforts have been carried out over the years to develop cost-efficient and sustainable processes for furfural production $^{[12,13]}$. In this arena not only the production of furfural needs to be optimized, but it is also necessary to avoid its degradation, which may occur by resinification, a reaction of furfural with its precursors, or condensation reactions between furfural units. ${ }^{[11]}$ Biphasic systems are commonly employed in continuous processes to improve furfural yields, achieved by decreasing the occurrence of secondary reactions. In these systems, furfural is produced in aqueous media and continuously extracted to the organic phase to which it has higher affinity. ${ }^{[14]}$ Conventional solvents such as methyl isobutyl ketone (MIBK) ${ }^{[15]}$, tetrahydrofuran (THF) ${ }^{[16]}$ and cyclopentyl methyl ether (CPME) ${ }^{[17]}$ have been used for this purpose. More recently, bio-based solvents, such as $\mathrm{Y}$-valerolactone $(\mathrm{GVL})^{[7,9]}$ and 2methyltetrahydrofuran $(2-\mathrm{Me}-\mathrm{THF})^{[6,18,19]}$ have been applied as greener alternatives.

In what concerns the furfural production from hemicelluloses, improved furfural yields have been obtained using biphasic systems and microwave-assisted reactions. ${ }^{[7,16]}$ Yang et al. ${ }^{[16]}$ reported a furfural yield of $64.0 \%$, using microwave heating, and a $\mathrm{H}_{2} \mathrm{O}$-THF biphasic system containing $\mathrm{NaCl}$ and $\mathrm{AlCl}_{3} \cdot 6 \mathrm{H}_{2} \mathrm{O}$ at $140{ }^{\circ} \mathrm{C} \cdot{ }^{[16]}$ Also featuring microwave-induced reactions, Yang et al. ${ }^{[7]}$ obtained $87.8 \%$ of furfural yield using a $\mathrm{GVL} / \mathrm{H}_{2} \mathrm{O}$ solvent system at $130{ }^{\circ} \mathrm{C}$, with $\mathrm{Al}_{2}\left(\mathrm{SO}_{4}\right)_{3}$ as catalyst. ${ }^{[7]}$ However, in both 
studies, long reaction times were used, from 45 minutes to $1 \mathrm{~h}$, [7,16] and catalysts can be easily deactivated in aqueous solution or biphasic systems containing salts. ${ }^{[14]}$ To overcome this drawback, the scientific community has been looking for other approaches, such as the use of supercritical solvents to dehydrate hemicellulose $(68 \%$ furfural yield using xylose at $230^{\circ} \mathrm{C}$ and $\left.12 \mathrm{MPa}\right),{ }^{[20]}$ or by the use of neoteric solvents, such as ionic liquids (ILs) ${ }^{[21,22]}$. The ILs 1-butyl-3-methylimidazolium hydrogen sulphate and 1-ethyl-3-methylimidazolium hydrogen sulphate were applied as acid catalysts, allowing $31 \%$ of furfural yield from wheat straw at $161^{\circ} \mathrm{C}$ and $104.5 \mathrm{~min}$ [21], and $84 \%$ of furfural yield from xylose at $100{ }^{\circ} \mathrm{C}$ and $6 \mathrm{~h}^{[22]}$. However, the furfural yields are still bellow to those obtained by the use of biphasic systems and heterogeneous catalysis.

Deep eutectic solvents (DES), another type of neoteric solvents, can also be applied and designed to have acidic characteristics, thus being able to act as catalysts in furfural production. DES were first proposed by Abbott et al. ${ }^{[23]}$, being composed of an hydrogen bond acceptor (HBA) and an hydrogen bond donor (HBD) species. They were initially reported as mixtures of two or more solid compounds that form a eutectic mixture deviating from ideality, thus presenting a significant decrease on the melting temperature. These solvents can be easily prepared by simply mixing, at appropriate ratio, the compounds required to create the desired eutectic mixture at a given temperature. ${ }^{[2]}$ Furthermore, DES have a "designer solvent" character by the proper selection of HBAs and HBDs ${ }^{[25,26]}$ and may display low toxicity if properly designed. ${ }^{[27]}$

DES have been used as solvents for polysaccharide modifications and processing ${ }^{[28]}$ and as catalytic media. ${ }^{[29,30]}$ Regarding furfural production in DES media, to the best of our knowledge, only a recent work reporting the use of the DES composed of cholinium chloride $([\mathrm{Ch}] \mathrm{Cl})$ and oxalic acid, but still requiring a Lewis acid as catalysts, i.e. $\mathrm{AlCl}_{3} \cdot 6 \mathrm{H}_{2} \mathrm{O}$, has been found. ${ }^{[31]}$ The authors used a biphasic system using MIBK within a continuous process, leading to a furfural yield of $55.5 \%$, obtained at $100^{\circ} \mathrm{C}$ from xylans. ${ }^{[31]}$ Although some drawbacks are associated with the conditions used, namely the inherent toxicity of oxalic acid, ${ }^{[32]}$ this study opens the door for the effective use of DES in furfural production. If a DES with acidic characteristics can be chosen, the DES itself can act as both the solvent and the catalyst (not requiring the use of the $\mathrm{AlCl}_{3} \cdot 6 \mathrm{H}_{2} \mathrm{O}$ catalyst as attempted by the authors $\left.{ }^{[31]}\right)$. This hypothesis is further supported by the unintentional production of small amounts of furfural when attempting biomass delignification with a DES composed of cholinium chloride and lactic acid. ${ }^{[33,34]}$ Based on these evidences, in this work, we designed a sustainable process for furfural production from xylans, where DES can act both as solvents and catalysts. DES composed of [Ch]Cl and malic acid ([Ch]Cl:MA) or [Ch]Cl and glycolic acid ([Ch]Cl:GA) were investigated. These acids were chosen due to their greener credentials ${ }^{[35,36]}$ and lower viscosity (when compared e.g. with citric acid). ${ }^{[36]}$ The different DES, with different proportions of the acids were tested and relevant operational conditions were optimized, namely solid/liquid ( $\mathrm{S} / \mathrm{L}$, biomass/solvent) ratio, temperature, microwave heating, water content, and amount of acid in the DES. After identifying the most promising DES and operational conditions, GLV was added with the initial goal of decreasing the reaction activation energy, as reported by Delbecq et al. ${ }^{[12]}$ Finally, the recovery of furfural was investigated, either by direct distillation or distillation after a back-extraction step, further allowing the solvents recyclability.

\section{Results and Discussion}

Xylan from beechwood was used as the substrate for the acidic hydrolysis and dehydration into furfural using two acidic DES ([Ch]Cl:MA and [Ch]Cl:GA) with different proportions of the acid. First, reactions were carried out with conventional heating and the best DES were identified. Furfural yield was calculated in moles of furfural in relation to the number of moles of xylose present in the xylan sample used. Parameters such as solid/liquid (S/L, biomass/solvent) ratio, temperature, and water content have been optimized to improve the furfural production. Furthermore, aiming at improving the process sustainability, microwave-assisted reactions were then carried out with the best DES. Then, the use of GLV was investigated with the initial goal of avoiding the furfural degradation and to improve its yield. The recovery of furfural and the solvents recyclability was finally attempted, and the DES integrity during the recycling process was appraised.

\section{Xylan conversion into furfural with conventional heating}

The production of furfural from xylan in acidic DES was initially evaluated with the DES [Ch]Cl:MA and [Ch]Cl:GA. The solidliquid phase diagrams of [Ch] $\mathrm{Cl}: \mathrm{MA}$ and [Ch]Cl:GA, where both starting materials are solid at room temperature have been reported by Crespo et al., ${ }^{[37]}$ demonstrating that this system deviates from ideality behaving like a DES. In this first screening, distinct conditions were evaluated, namely the xylan/DES weight fraction ratio $(0.050$ and $0.175 \mathrm{w} / \mathrm{w})$, temperature $(90$ and $130^{\circ} \mathrm{C}$ ), acid content in the DES (molar ratio of $1: 2$ and $1: 3$ of $[\mathrm{Ch}] \mathrm{Cl}$ in respect to MA or GA), and water content (due to its relevance to promote xylan hydrolysis ${ }^{[12]}$ ). DES were prepared without previous drying, although determining their water content (2.5 wt.\%). Aiming at decreasing their viscosity, DES with $5 \mathrm{wt} . \%$ of water were also prepared. The system [Ch]Cl:Lactic acid in the molar ratio of 1:10 with $15 \mathrm{wt} . \%$ of water was also prepared for comparison purposes, as furfural production has been reported with this DES when addressing biomass delignification. ${ }^{33,34]}$

The furfural production yields obtained in this first screening are depicted in Figure 1. The results show that [Ch]Cl:MA is more efficient as catalyst and solvent than [Ch]Cl:GA, leading to furfural yields up to $44.87 \%$. Taking into consideration that GA and MA have a similar first pKa's $\left(\mathrm{pKa}_{1}=3.61 \mathrm{vs} \mathrm{pKa}_{1}=3.51\right),{ }^{[38}$ the higher conversions in [Ch]Cl:MA can be linked to the higher acidity of the media afforded by the dicarboxylic MA $\left(\mathrm{pKa}_{2}=5.03\right)$. Interestingly, and despite the high content of lactic acid, the furfural yields obtained with the [Ch]Cl:LA $(1: 10, \mathrm{pKa}=3.86)^{[38]}$ were considerably lower (<25\%). Additionally, high temperatures seem to boost furfural yield, as appraised by comparing the results obtained at 90 and $130{ }^{\circ} \mathrm{C}$. A lower $\mathrm{S} / \mathrm{L}$ ratio is also relevant, resulting in higher furfural yields, as seen by comparing the results at $130^{\circ} \mathrm{C}$ and $8 \mathrm{~h}$, due to a better access of the solvent to xylan. 


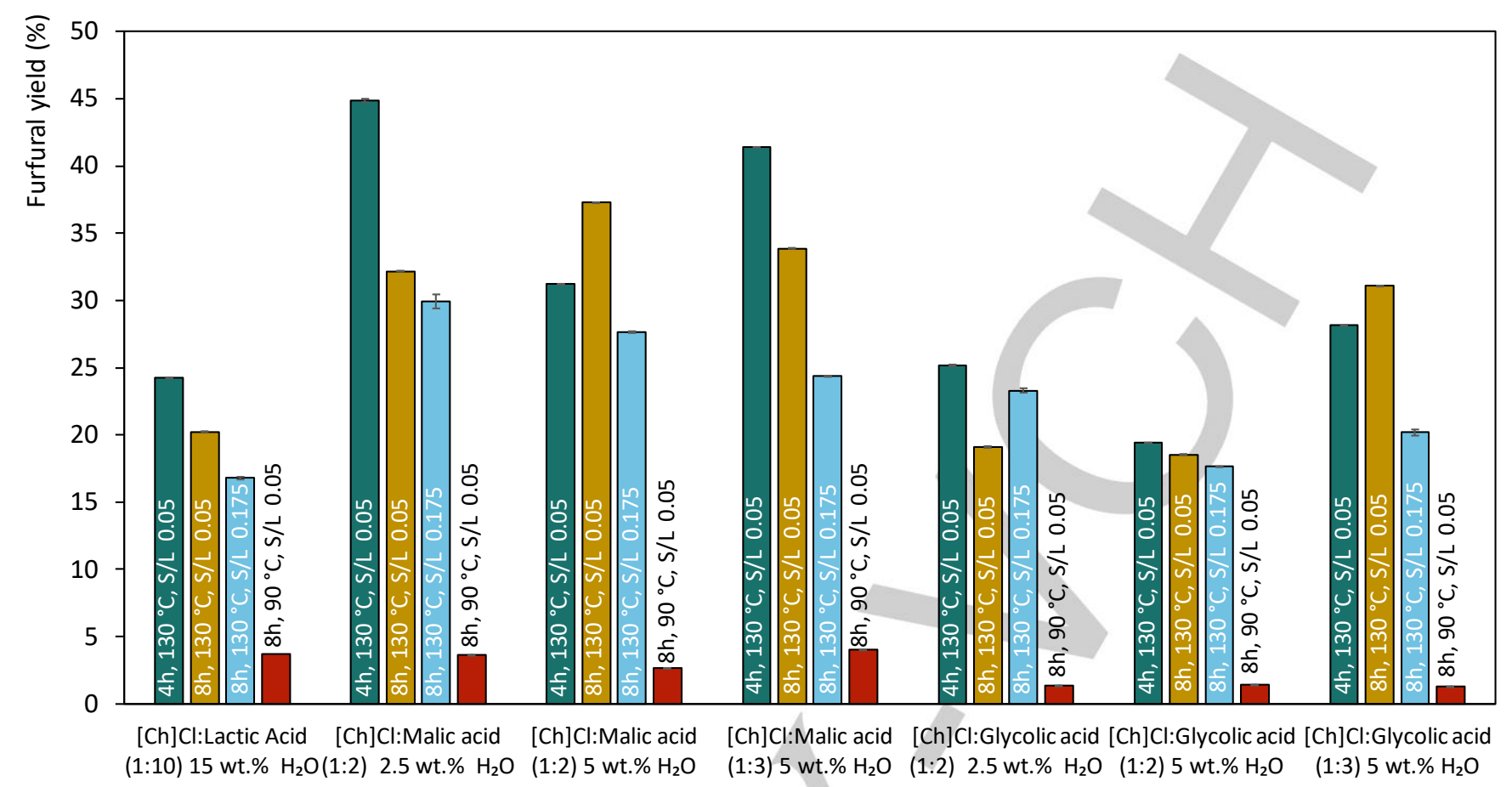

Figure 1. Furfural yields obtained with conventional heating at different: reaction time, $\mathrm{S} / \mathrm{L}$ ratio and temperature $\left(\square 4 \mathrm{~h}, 130^{\circ} \mathrm{C}, \mathrm{S} / \mathrm{L}\right.$ ratio $=0.050, \square 8 \mathrm{~h}$, $130^{\circ} \mathrm{C}, \mathrm{S} / \mathrm{L}$ ratio $=0.050,-8 \mathrm{~h}, 130^{\circ} \mathrm{C}, \mathrm{S} / \mathrm{L}$ ratio $=0.175,-8 \mathrm{~h}, 90^{\circ} \mathrm{C}, \mathrm{S} / \mathrm{L}$ ratio $=0.050$ ).

Although good results were obtained, [Ch]Cl:MA (1:2) is still a viscous solvent, thus requiring higher energetic inputs which could negatively contribute to the mass transfer phenomena. Knowing that water content is important for the xylan hydrolysis into xylose ${ }^{[12]} 5 \mathrm{wt} . \%$ of added water were then tested in the [Ch]Cl:MA $(1: 2)$ system, whose results are displayed in Figure 1 . An increased amount of water resulted in a slight decrease in the furfural yield, which is due to the decrease of the system acidity. Therefore, with the aim of increasing the furfural yield while decreasing the DES viscosity, the molar ratio of [Ch]Cl to MA or to GA of $1: 3$ with $5 \mathrm{wt} . \%$ of water was then experienced - cf. Figure 1. The increase of the solvent acidity resulted in an increase in the furfural yield up to $41.42 \%$, achieved with the DES [Ch]Cl:MA. Overall, under the best conditions, i.e. a molar ratio of $1: 3$ of $[\mathrm{Ch}] \mathrm{Cl}$ to $\mathrm{MA}$, with 5 wt.\% of water at $130^{\circ} \mathrm{C}$ and $4 \mathrm{~h}$ of reaction time, a furfural yield of $44.87 \%$ is achieved. This value is comparable to the yields obtained in studies using mineral acids, like $\mathrm{HCl}$, at higher temperature $\left(\approx 180{ }^{\circ} \mathrm{C}\right) .{ }^{[15,39]}$ The high furfural yield obtained is most probably related with the findings of De Oliveira Vigier and co-workers, ${ }^{[40]}$ who demonstrated that in presence of $[\mathrm{Ch}] \mathrm{Cl}$ the production of furfural is fostered by the formation of a choline xyloside intermediate.

\section{Xylan conversion into furfural with Microwave Heating}

The furfural yields obtained with conventional heating are already promising when compared with the literature, in which lower yields have been achieved using higher temperatures and in presence of strong acids as catalysts. ${ }^{[14]}$ Nonetheless, the furfural yield obtained under the investigated conditions is still below $50 \%$, and $4 \mathrm{~h}$ of reaction time are required. Aiming at improving the furfural yield, while reducing the reaction time, microwave-assisted reactions were investigated with the DES [Ch]Cl:MA (1:3), with 5 wt.\% of water. Reactions were initially performed at 130,140 and $150{ }^{\circ} \mathrm{C}$ for 2.5, 5.0 and 7.5 min (Figure 2). The results obtained clearly show that the best furfural yields were obtained at $150{ }^{\circ} \mathrm{C}$ for 2.5 $\mathrm{min}$; for longer reaction times furfural yield decreases most likely due to furfural degradation.

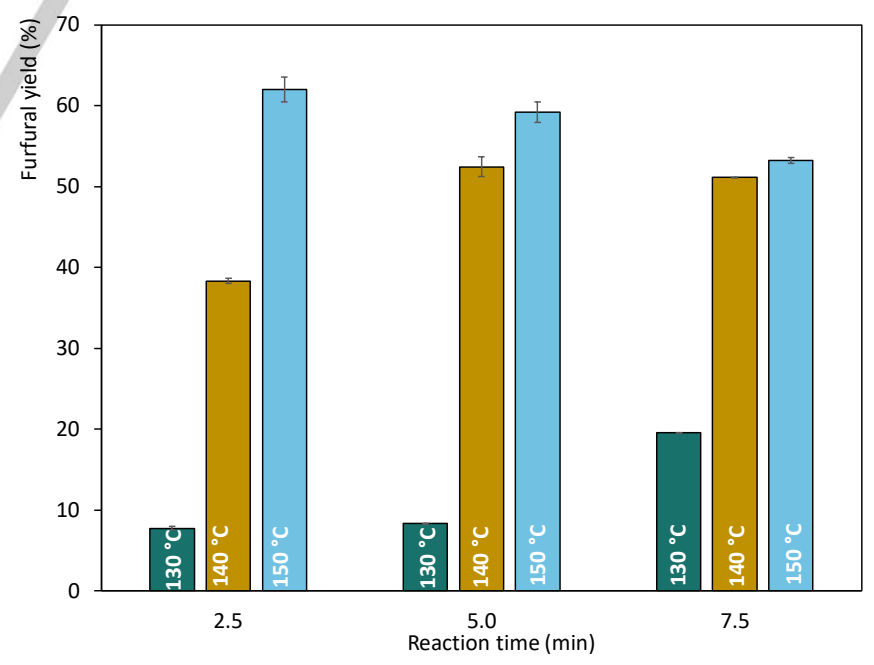

Figure 2. Furfural yields obtained with microwave-assisted reactions using [Ch]Cl:MA (1:3) +5 wt. $\% \mathrm{H}_{2} \mathrm{O}$ at different reaction times and temperatures $\left(\square 130^{\circ} \mathrm{C},-140^{\circ} \mathrm{C},-150^{\circ} \mathrm{C}\right)$.

After these assays and with the aim of optimizing the reaction time, other reaction times closer to $2.5 \mathrm{~min}$ were tested (cf. Figure S1). However, it was found that $2.5 \mathrm{~min}$ is the optimal reaction time for furfural production under the selected conditions. It should be remarked that in all the studied assays the power pulse was bellow 
400W, demonstrating the capability of the DES to absorb microwave radiation and to decrease the energy required for the reaction to occur. The reported power pulse is also considerably lower when compared to those described in the literature using a single beam microwave reactor. ${ }^{[15]}$ Overall, the best results under microwave-assisted reactions were achieved with $2.5 \mathrm{~min}$ of reaction time at $150{ }^{\circ} \mathrm{C}$, leading to a furfural yield of $62.02 \%$.

The effect of water content under microwave heating was then addressed with the DES [Ch]Cl:MA (1:3), comprising 2.5, 5 and 10 wt. $\%$ of water at the best identified reaction conditions $\left(150^{\circ} \mathrm{C}\right.$ and $\mathrm{S} / \mathrm{L}$ ratio $=0.050)$ and at two different reaction times (1.5 and 2.5 $\mathrm{min})$. As verified before with conventional heating, the results shown in Figure 3 reveal that water plays a significant role in this process. Under microwave heating, there is a positive effect of the addition of water to the DES up to $5 \mathrm{wt} . \%$, improving the furfural yield. However, higher water contents, i.e. 10 wt.\%, are not beneficial and decrease furfural yield. These results are in agreement with what was observed under conventional heating: the addition of water decreases the solvent viscosity but at the same time decreases the solvent acidity. Therefore, there is an intermediate amount of water that leads to improved furfural yields.

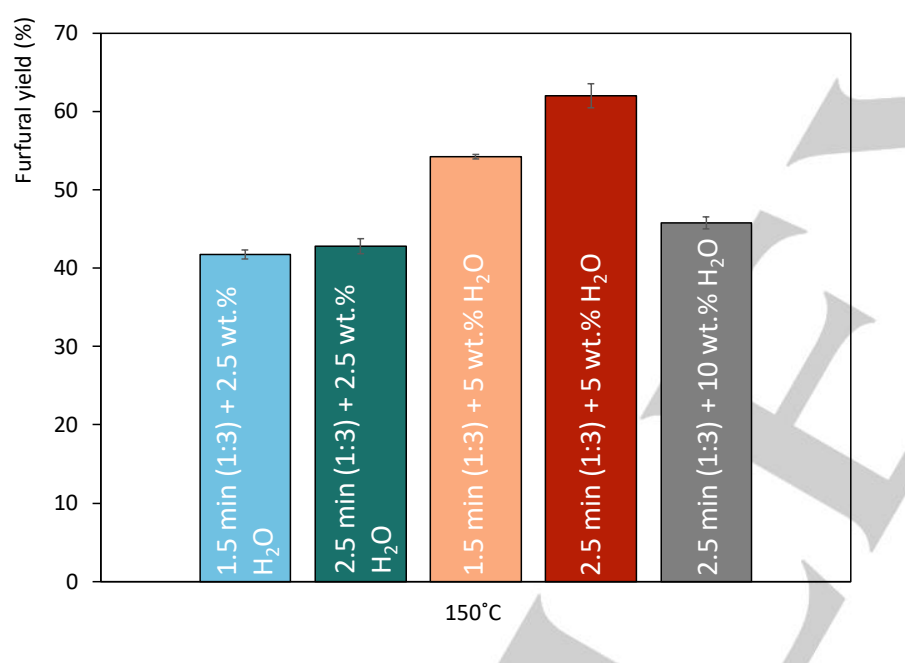

Figure 3. Effect of water in furfural yields using [Ch] Cl:MA (1:3), at $150{ }^{\circ} \mathrm{C}$ and $\mathrm{S} / \mathrm{L}$ ratio $=0.050\left(-1.5 \mathrm{~min}+2.5 \mathrm{wt} . \% \mathrm{H}_{2} \mathrm{O},-2.5 \mathrm{~min}+2.5 \mathrm{wt} . \% \mathrm{H}_{2} \mathrm{O}\right.$, $1.5 \mathrm{~min}+5 \mathrm{wt} . \% \mathrm{H}_{2} \mathrm{O}$, - $2.5 \mathrm{~min}+5 \mathrm{wt} . \% \mathrm{H}_{2} \mathrm{O},=2.5 \mathrm{~min}+10 \mathrm{wt} . \%$ $\left.\mathrm{H}_{2} \mathrm{O}\right)$.

\section{Addition of $\mathrm{y}$-valerolactone aiming the increase of furfural} yield

The use of bio-based solvents such as GVL has been reported by Dumesic and co-workers ${ }^{[41]}$ to be beneficial for furfural production from xylose using Brønsted acids. In particular, the xylose dehydration occurs faster in GVL than in water, which in turn minimizes the formation of degradation products, thus boosting furfural yield. ${ }^{[41]}$ Moreover, it has been reported that GVL decreases the activation energy required for the dehydration of xylose into furfural. ${ }^{[12]}$ On the other hand, Yang et al. ${ }^{[7]}$ reported the possibility of having a biphasic system between water and GVL, which would be ideal for the continuous separation of furfural during microwaveassisted reactions.

Based on these evidences, the production of furfural using the previously optimized conditions in different GVL:DES proportions was studied, whose results are shown in Figure 4. However, when testing a GVL:DES system at a weight ratio of $4: 1$, no biphasic system was formed, and furfural yields below $40 \%$ were obtained. Interestingly, when decreasing the GLV content (GLV:DES of 1:1, $1: 2,1: 2.5$ and $1: 3 \mathrm{w}: \mathrm{w})$ higher yields were obtained. With the system GLV:DES 1:2 (w:w), furfural yields up to $75.09 \%$ can be reached. These results demonstrate the advantages of using GVL at appropriate conditions, leading to an increase of $\approx 15 \%$ in furfural yield. This increase in yield by the presence of GVL further confirms the above mentioned advantages of using GVL as co-solvent. ${ }^{[12,41]}$ it should be remarked that the addition of Me-THF during the MW irradiation was also tested (results not shown). However, the furfural yields obtained were considerably lower than those obtained with GVL.

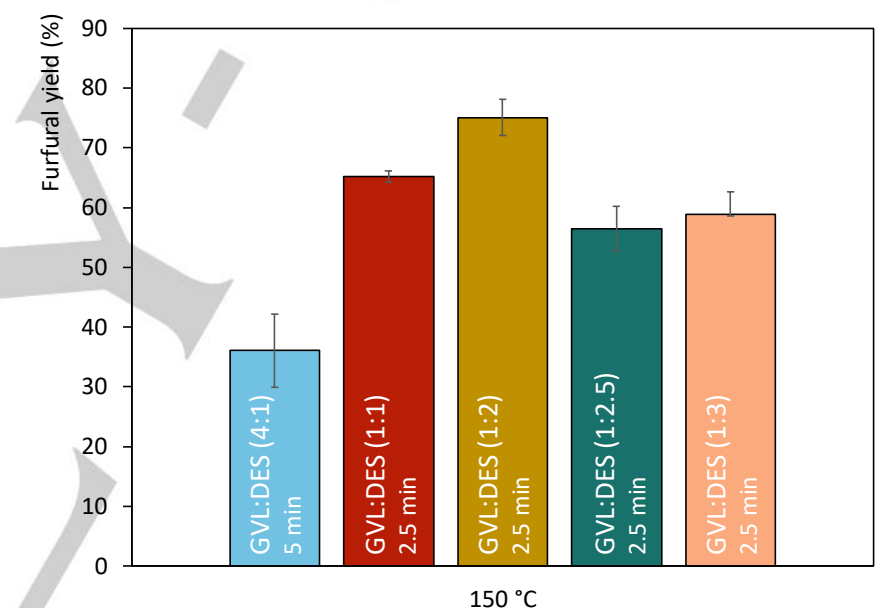

Figure 4. Effect of the ratio of GVL in furfural yields using the DES [Ch]Cl:MA $(1: 3)+5$ wt. $\% \mathrm{H}_{2} \mathrm{O}$ at $150{ }^{\circ} \mathrm{C}, \mathrm{S} / \mathrm{L}$ ratio $=0.050$ ( $\square$ GVL:DES (4:1) $5 \mathrm{~min}$, GVL:DES (1:1) $2.5 \mathrm{~min}, \approx \mathrm{GVL}: \mathrm{DES}(1: 2) 2.5 \mathrm{~min}$, $\approx$ GVL:DES (1:2.5) 2.5 $\mathrm{min}, \approx \mathrm{GVL}: \mathrm{DES}(1: 3) 2.5 \mathrm{~min})$

To the best of our knowledge this is the highest furfural yield (75\%) obtained in a short reaction time $(2.5 \mathrm{~min})$ and using xylan as the raw material. Furthermore, for the first time, it is shown that acidic DES can be simultaneously used as solvents and catalysts in furfural production directly from xylose. These results open the path to investigate a more integrated strategy using DES in biorefinery processes, that also comprises furfural recovery and DES recycling as shown below.

\section{Proof of Concept: Furfural recovery and DES recycling}

With the purpose of fostering the sustainability of the developed process, the recovery of furfural from the DES-GVL solvent and the solvent recycling were finally addressed. In order to recover furfural from the reaction media, and since no biphasic system was formed with GVL under the optimal conditions for furfural production, two strategies were followed: (i) direct distillation of furfural from the 
DES-GVL solvent; and (ii) liquid-liquid extraction (1:1 weight ratio) using a bio-based solvent, namely 2-Me-THF, which is immiscible with the DES, followed by distillation. The distillation step seems to be an adequate strategy due to the boiling temperatures differences of 2-Me-THF, furfural, GVL, and the DES components (MA, GA, [Ch] Cl degrades above $302^{\circ} \mathrm{C}$ ): $80^{\circ} \mathrm{C}, 169^{\circ} \mathrm{C}, 208^{\circ} \mathrm{C}$, $306^{\circ} \mathrm{C}$ and $265^{\circ} \mathrm{C}$, respectively. ${ }^{[42]}$

The steps required for the two recovery and recycling strategies are summarized in Figure 5. In the first strategy, furfural is directly distilled from the DES-GVL mixture. In the strategy where 2-MeTHF is applied as a back-extraction solvent, distillation is applied to this solvent (lower boiling point than furfural). The furfural recovery yields by both strategies are depicted in Figure 6. Remarkably, $89.5 \%$ of furfural can be recovered by distillation from the 2-MeTHF solvent, whereas $75.7 \%$ of furfural can be obtained from the DES:GVL solvent. Better results are achieved with the recovery of furfural from 2-Me-THF, although requiring and additional step when compared with the other strategy. Furthermore, this strategy allows faster extraction and stabilization of furfural by removing it from the acidic media, and therefore was chosen as the ideal methodology to be used in further assays. The confirmation of the purity of the recovered furfural was performed by ${ }^{1} \mathrm{H}$ and ${ }^{13} \mathrm{C} N M R$, being also evidenced in the HPLC spectra at $268 \mathrm{~nm}$, whose results are given in Figure S2 and S3. Although distillation is often mentioned in the literature as a possible way to recover furfural, ${ }^{[42]}$ the actual reports that carried out the furfural recovery are however scarce. Nonetheless, the reported furfural recovery from the 2-MeTHF fraction is similar to optimized continuous processes. ${ }^{[43]}$

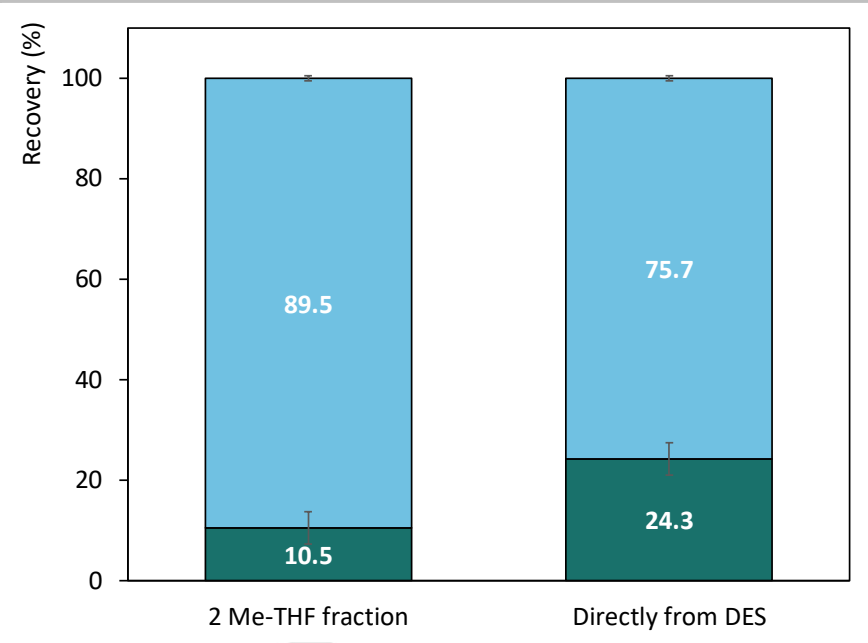

Figure 6. Furfural recovery by reduced pressure distillation from the 2-MeTHF and GVL-DES solvents. ( recovered furfural and $₫$ furfural remaining in 2-Me-THF or GVL-DES fractions).

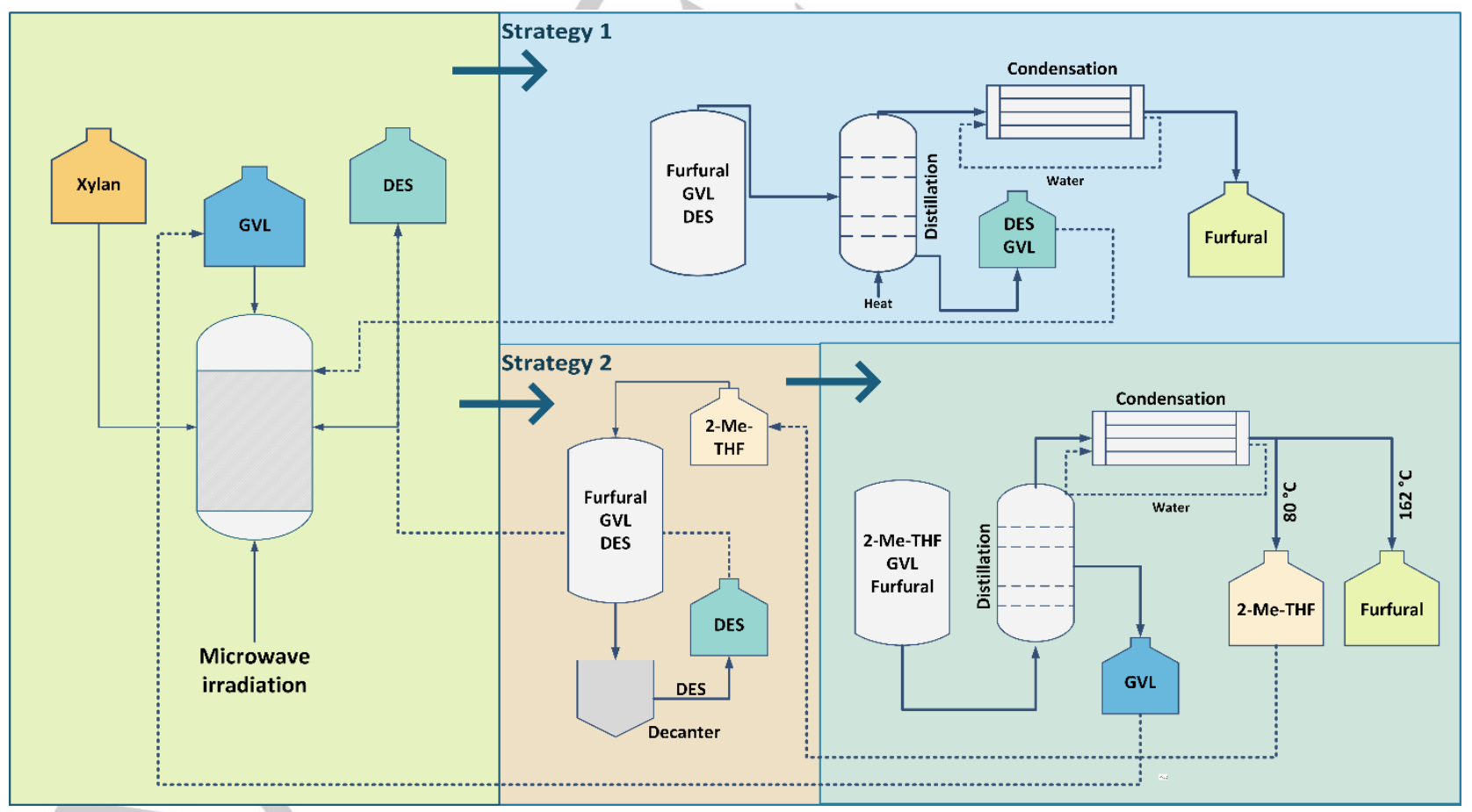

Figure 5. Scheme depicting the two strategies that can be adopted for the recovery of furfural and solvents recycling. 
After the successful recovery of furfural, the recyclability of the DES and DES/GVL solvent was evaluated in additional reactions to produce furfural from xylan, being the results obtained depicted in Figure 7. The DES stability/integrity was confirmed through ${ }^{1} \mathrm{H}$ and ${ }^{13} \mathrm{C}$ NMR throughout the different recycles, being kept with and without GVL. Although furfural has a high affinity to the 2-MeTHF organic phase, $94.6 \%$ being extracted, a small fraction of furfural is still present in the recycled solvent. Accordingly, a slight decrease in the furfural yield is observed as the number of recycling steps increases. Nonetheless, in at least up to three recycles of the DES-based solvent, the furfural yields obtained in the 2-Me-THF fraction can be kept above $69.0 \%$, which are higher than those obtained in most industrial processes developed up to date. ${ }^{[4]}$

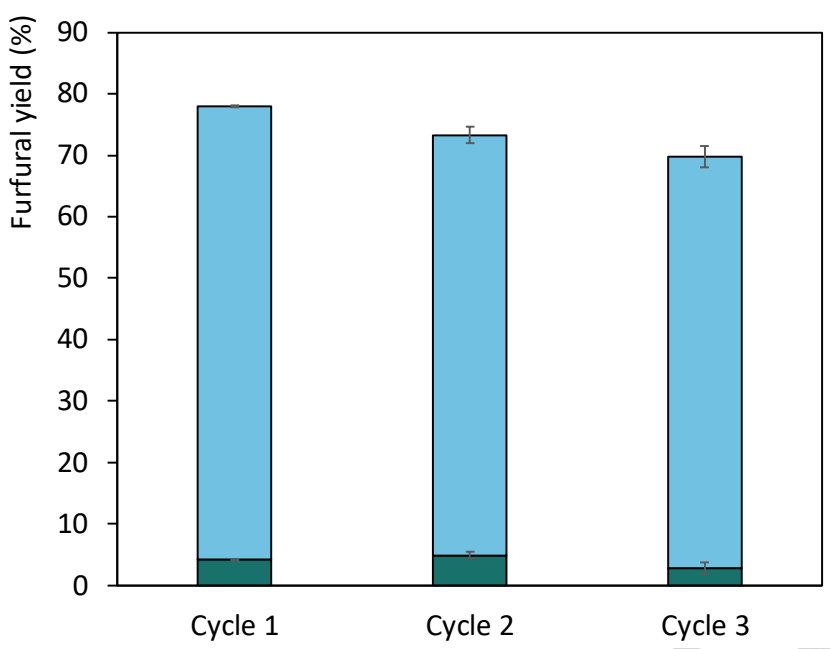

Figure 7. Furfural yields using the GVL:DES $(1: 2, w: w)$ solvent with the DES [Ch]Cl:Malic acid $(1: 3)+5$ wt. $\% \mathrm{H}_{2} \mathrm{O}$ at $150^{\circ} \mathrm{C}, \mathrm{S} / \mathrm{L}$ ratio $=0.05,2.5$ $\min$ ( $\square$ furfural yield in the 2-Me-THF fraction and $₫$ furfural remaining in the DES-based solvent).

\section{Conclusions}

In this work, a new process for furfural production from xylan using DES, acting both as solvent and catalyst, was designed and validated. DES composed of [Ch]Cl and MA and GA at different molar ratio, and different operational conditions such as time of reaction, solid/liquid (biomass/solvent) ratio, presence of water and GVL, and conventional or microwave heating, were investigated. The best furfural yields (>75\%) were obtained with the DES [Ch]Cl:Malic Acid (1:3, molar ratio) +5 wt.\% of water in a weight ratio of $2: 1$ with GVL under microwave heating (2.5 min of reaction time and a solid/liquid ratio of 0.050 ). The use of water and GVL contributed to improved yields by decreasing the solvent viscosity and by potentiating the xylan hydrolysis into xylose and by decreasing the degradation of furfural. Finally, furfural was recovered by distillation from the DES-GLV solvent or from 2-MeTHF after a back-extraction step. The second approach was found to lead to higher recovery yields of furfural (up to $89.5 \%$ ), further allowing the DES-GLV solvent recycling for at least 3 times, in which the furfural production yield is kept above $69 \%$ in the 2 Me-THF fraction.

The process here developed has potential to be scaled-up, offering several advantages when compared with the currently used industrial processes, namely a shorter time of reaction, use of less harsh conditions, and use of a bio-based and recyclable solvents/catalysts. When compared to other works already reported in the literature, to the best of our knowledge, this is the fastest and highest yield process developed up to date to produce furfural.

\section{Experimental Section}

\section{Chemicals}

Cholinium chloride ([Ch]Cl) ( $\geq 99 \%$ purity), furfural ( $\geq 99 \%$ purity), $\mathrm{Y}$-valerolactone (GVL) (98\% purity) and lactic acid (LA, 85\% (w/v)) were supplied by Sigma (USA). DL-Malic acid (MA, 99.5\% purity) was obtained from Panreac (Spain) and glycolic acid (GA, purity 99\%) was obtained from Acros Organics (USA). 2Methytetrahydrofuran (2-Me-THF, 99\% purity) was obtained from Alfa Aeasar (Germany). Commercial beechwood xylan (9.39 wt.\% humidity) was purchased from Apolo Scientific (UK).

\section{DES preparation}

[Ch]Cl was used as the hydrogen bond acceptor (HBA) and malic acid (MA), glycolic acid (GA) and lactic acid (LA) as hydrogen bond donors (HBD). The HBA and HBDs were prepared by weight at the desired molar ratio in sealed glass vials. The water content of all compounds was determined through a Metrohm 831 Karl Fisher coulometer. Mixtures in closed vials were then heated up to $70^{\circ} \mathrm{C}$ and stirred for at least $1 \mathrm{~h}$ until a transparent liquid was formed. Mixtures were cooled down to room temperature and kept in sealed glass vials up to use. In assays where water was used (5 and 10 wt.\%), it was added after the DES preparation.

\section{Xylan hydrolysis and production of furfural}

The furfural production reactions were carried out in a Radleys Tech carousel in $30 \mathrm{~mL}$ glass vials, with a fixed stirring of $400 \mathrm{rpm}$. Two xylan/DES weight ratios were tested, namely 0.050 and 0.175 . The reactions were carried out at 90 or $130^{\circ} \mathrm{C}$, and after the established reaction time $(2,4$ or $8 \mathrm{~h})$ the samples were left to cool down, then diluted appropriately with deionized water and filtered through a nylon Whatman filter of $0.45 \mu \mathrm{m}$ pore into appropriate HPLC glass vials. Triplicates were carried out in all assays. Table S1 summarizes the tested conditions.

The microwave-assisted reactions were carried out in a Monowave 300 microwave synthesis reactor from Anton Paar (Austria). Heating was applied as fast as possible, with a heating time was always bellow $1 \mathrm{~min}$. The best solid/liquid ratio was selected from the previous results (0.050) and both xylan and DES mixtures were weighted and prepared in sealed vials $(10 \mathrm{~mL})$. Then, vials were placed in the microwave reactor at a fixed stirring of $600 \mathrm{rpm}$ and removed at the end of the established reaction times (1.5, 2, 2.5, 3.5, 5.0 and $7.5 \mathrm{~min})$. The tested conditions are summarized in Table S2. All reactions were carried out in triplicate and presented as average yield. 
With the goal of increasing the furfural production yield, the addition of GVL was tested under microwave irradiation. GVL was added to the most promising DES previously identified. GVL was weighted after xylans and added to the selected DES at several weight ratio in relation to the DES $(4: 1,1: 1,1: 2$ and $1: 3)$. These mixtures were then put into the microwave and left to react for the optimal time previously determined.

2-Me-THF was added after the reaction was stopped in a 1:1 ratio with the GVL/DES system. Afterwards the 2-Me-THF was removed and another cycle was performed with fresh solvent. Afterwards, the remaining DES fraction was separated and diluted with deionized water and the recovered 2-Me-THF was diluted with methanol. Samples were filtered using a nylon Whatman filter of $0.45 \mu \mathrm{m}$ pore into HPLC glass vials.

\section{Furfural Recovery and DES recycling}

Furfural was separated from the 2-Me-THF organic phase by distillation. Since 2 -Me-THF has a lower boiling point $\left(\approx 80^{\circ} \mathrm{C}\right)$ than furfural $\left(\approx 162^{\circ} \mathrm{C}\right)$, it is distilled first followed by furfural which has a lower boiling point than GVL $\left(208{ }^{\circ} \mathrm{C}\right) . .^{[42]}$ The distilled furfural was recovered, weighed and the furfural yield calculated. The recovered furfural was then re-dissolved in water, diluted and filtered through a nylon Whatman filter of $0.45 \mu \mathrm{m}$ pore into HPLC glass vials. The recovered DES-based solvent was used in at least three more cycles of xylan conversion in order to address the solvent recyclability on the furfural production yield. Furthermore the solvents stability was followed through ${ }^{1} \mathrm{H}$ and ${ }^{13} \mathrm{C}$ NMR. The obtained furfural was compared with a reference sample of furfural by ${ }^{1} \mathrm{H}$ and ${ }^{13} \mathrm{C}$ NMR. The ${ }^{1} \mathrm{H}$ NMR and ${ }^{13} \mathrm{C}$ NMR spectra were recorded using a Bruker Avance 300 at $300.13 \mathrm{MHz}$ and $75.47 \mathrm{MHz}$, respectively, using deuterated water as solvent and trimethylsilyl propanoic acid (TMSP) as internal reference.

\section{Furfural quantification}

The quantification of furfural in each sample was carried out by HPLC-DAD (Shimadzu, model PROMINENCE). HPLC analyses were performed with an analytical $C_{18}$ reverse-phase column (250 $\times 4.60 \mathrm{~mm}$ ), Kinetex $5 \mu \mathrm{m} \mathrm{C}_{18} 100 \AA$, from Phenomenex. The mobile phase consisted of $20 \%$ of methanol and $80 \%$ of ultra-pure water. The separation was performed in isocratic mode, at a flow rate of $0.8 \mathrm{~mL} \cdot \mathrm{min}^{-1}$ and an injection volume of $10 \mu \mathrm{L}$. Furfural detection was carried out at $268 \mathrm{~nm}$ with a diode array detector (DAD). Each sample was analyzed at least in duplicate. The column oven and the autosampler were operated at a controlled temperature of $35^{\circ} \mathrm{C}$. Calibration curves were established with pure furfural dissolved in water. Furfural yield is expressed in moles of furfural in relation to the number of moles of xylose present in the xylan sample used.

\section{Acknowledgements}

This work was developed within the scope of the project CICECOAveiro Institute of Materials, FCT Ref. UID/CTM/50011/2019, financed by national funds through the FCT/MCTES. The research leading to reported results has received funding from FCT through the projects DeepBiorefinery (PTDC/AGR-
TEC/1191/2014) and MultiBiorefinery (POCl-01-0145-FEDER016403), and through C. Freire Researcher contract (CEECIND/00464/2017). E. S. Morais acknowledges FCT for the PhD grant SFRH/BD/129341/2017. The NMR spectrometers used are part of the National NMR Network (PTNMR) and are partially supported by Infrastructure Project № 022161 (cofinanced by FEDER through COMPETE 2020, POCI and PORL and FCT through PIDDAC.

\section{Conflict of Interest}

The authors declare no conflict of interest.

Keywords: xylans • deep eutectic solvents • furfural • microwave heating $\cdot$ green solvents

\section{References}

\section{[1] R. A. Sheldon, Green Chem. 2016, 19, 18-43.}

[2] G. Fiorentino, M. Ripa, N. Parthenope, Biofuels, Bioprod. Biorefining 2016, 11, 195-214.

[3] T. Werpy, G. Petersen, A. Aden, J. Bozel, J. Holladay, J. White, A Manheim, Top Value Added Chemicals from Biomass Volume I Results of Screening for Potential Candidates from Sugars and Synthesis Gas Top Value Added Chemicals, 2004.

[4] X. Li, P. Jia, T. Wang, ACS Catal. 2016, 6, 7621-7640.

[5] J. H. Clark, Green Chem. 2007, 609, 603-609.

[6] W. Wang, J. Ren, H. Li, A. Deng, R. Sun, Bioresour. Technol. 2015 183, 188-194.

[7] T. Yang, Y. H. Zhou, S. Z. Zhu, H. Pan, Y. B. Huang, ChemSusChem 2017, 10, 4066-4079.

[8] A. Mittal, S. K. Black, T. B. Vinzant, O. Brien, M. P. Tucker, D. K. Johnson, ACS Sustain. Chem. Eng. 2017, 5, 5694-5701.

[9] W. Li, Y. Zhu, Y. Lu, Q. Liu, S. Guan, H. min Chang, H. Jameel, L. Ma, Bioresour. Technol. 2017, 245, 258-265.

[10] M. Dashtban, A. Technologies, M. Dashtban, J. Sci. Technol. For. Prod. Process. 2015, 2, 44-53.

[11] R. Karinen, K. Vilonen, M. Niemelä, ChemSusChem 2011, 4, 1002 1016

[12] F. Delbecq, Y. Wang, A. Muralidhara, K. El Ouardi, G. Marlair, C. Len, Front. Chem. 2018, 6, 1-29.

[13] Y. Wang, T. Len, Y. Huang, A. Diego Taboada, A. N. Boa, C. Ceballos F. Delbecq, G. Mackenzie, C. Len, ACS Sustain. Chem. Eng. 2017, 5, 392-398.

[14] Y. Luo, Z. Li, X. Li, X. Liu, J. Fan, J. H. Clark, C. Hu, Catal. Today 2019, 319, 14-24.

[15] N. Sweygers, J. Harrer, R. Dewil, L. Appels, J. Clean. Prod. 2018 187, 1014-1024

[16] Y. Yang, C. W. Hu, M. M. Abu-Omar, ChemSusChem 2012, 5, 405410.

[17] G. Gómez Millán, S. Hellsten, A. W. T. King, J. P. Pokki, J. Llorca, H. Sixta, J. Ind. Eng. Chem. 2019, 72, 354-363.

[18] Q. Lin, H. Li, X. Wang, L. Jian, J. Ren, C. Liu, R. Sun, Catalysts 2017 7,118

[19] C. M. Cai, N. Nagane, R. Kumar, C. E. Wyman, Green Chem. 2014 $16,3819-3829$.

[20] K. Gairola, I. Smirnova, Bioresour. Technol. 2012, 123, 592-598. 
[21] A. V Carvalho, M. C. Lopes, R. Bogel-Łukasik, RSC Adv. 2015, 5, 47153-47164.

[22] S. Lima, P. Neves, M. M. Antunes, M. Pillinger, N. Ignatyev, A. A Valente, Appl. Catal. A Gen. 2009, 363, 93-99.

[23] A. P. Abbott, G. Capper, D. L. Davies, R. K. Rasheed, V. Tambyrajah, Chem. Commun 2003, 70-71.

[24] S. Khandelwal, Y. K. Tailor, M. Kumar, J. Mol. Liq. 2016, 215, 345386.

[25] B. Tang, K. Ho, Monatsh Chem 2013, 144, 1427-1454.

[26] Q. Zhang, K. De Oliveira Vigier, S. Royer, F. Jérôme, Chem. Soc. Rev. 2012, 41, 7108-46.

[27] Y. Dai, J. van Spronsen, G.-J. Witkamp, R. Verpoorte, Y. H. Choi, Anal. Chim. Acta 2013, 766, 61-8.

[28] O. A. El Seoud, A. Koschella, L. C. Fidale, S. Dorn, Biomacromolecules 2007, 8, 2629-2946.

[29] X. Tang, M. Zuo, Z. Li, H. Liu, C. Xiong, X. Zeng, ChemSusChem 2017, 10, 2696-2706.

[30] M. Zdanowicz, K. Wilpiszewska, T. Spychaj, Carbohydr. Polym. 2018, 200, 361-380.

[31] L. Zhang, H. Yu, H. Yu, Z. Chen, L. Yang, Chinese Chem. Lett. 2014 25, 1132-1136.

[32] C. Guo, K. E. McMartin, Toxicology 2005, 208, 347-355.

[33] X. Shen, J.-L. Wen, Q. Mei, X. Chen, D. Sun, T.-Q. Yuan, R.-C. Sun, Green Chem. 2018, 21, 275-283.

[34] C. Alvarez-Vasco, R. Ma, M. Quintero, M. Guo, S. Geleynse, K. K. Ramasamy, M. Wolcott, X. Zhang, Green Chem. 2016, 18, 51335141.

[35] M. Espino, M. de los Ángeles Fernández, F. J. V. Gomez, M. F. Silva, TrAC - Trends Anal. Chem. 2016, 76, 126-136.

[36] P. De Morais, F. Gonçalves, J. A. P. Coutinho, S. P. M. Ventura, ACS Sustain. Chem. Eng. 2015, 3, 3398-3404.

[37] E. A. Crespo, L. P. Silva, M. A. R. Martins, M. Bülow, O. Ferreira, G. Sadowski, C. Held, S. P. Pinho, J. A. P. Coutinho, Ind. Eng. Chem. Res. 2018, 57, 11195-11209.

[38] R. J. Ouellette, J. David, Rawn, in Org. Chem. - Struct. Mech. Synth., 2014, pp. 659-698.

[39] O. Yemiş, G. Mazza, Bioresour. Technol. 2011, 102, 7371-7378.

[40] S. Jiang, C. Verrier, M. Ahmar, J. Lai, C. Ma, E. Muller, Y. Queneau, M. Pera-Titus, F. Jérôme, K. De Oliveira Vigier, Green Chem. 2018 $20,5104-5110$

[41] E. I. Gürbüz, J. M. R. Gallo, D. M. Alonso, S. G. Wettstein, W. Y. Lim, J. A. Dumesic, Angew. Chemie - Int. Ed. 2013, 52, 1270-1274.

[42] Z. Zhang, ChemSusChem 2016, 9, 156-171.

[43] R. Xing, W. Qi, G. W. Huber, Energy Environ. Sci. 2011, 4, 2193 2205. 
Entry for the Table of Contents (Please choose one layout)

Layout 1:

\section{FULL PAPER}

DES composed of cholinium chloride and malic or glycolic acid can be used in the production of furfural from xylans with outstanding yields in very short periods of reaction time.

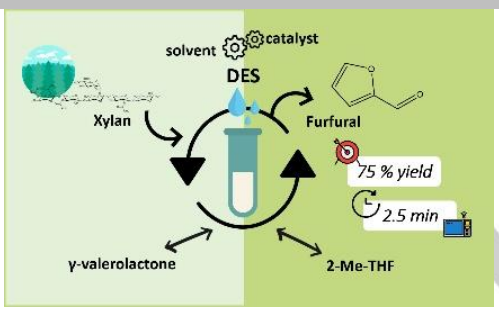

E. S. Morais, , M. G. Freire, C. S. R. Freire, J. A. P. Coutinho, and, A. J.D. Silvestre ${ }^{\star}$ Page No. - Page No.

Enhanced conversion of xylan into furfural using acidic deep eutectic solvents with dual solvent and catalyst behavior 